\title{
O Jogo e o Desenho digitais no Ensino da Educação Patrimonial
}

\author{
Digital Game and Drawing in Heritage Education Teaching
}

- Renan Leite Antiqueira

Instituto de Arquitetura e Urbanismo USP,

Brasil

renanlantiqueira@gmail.com

- Simone Helena Tanoue Vizioli

Instituto de Arquitetura e Urbanismo USP,

Brasil

simonehtv@sc.usp.br
Kauê de Macedo Antiqueira

Faculdade de Ciências UNESP, Brasil

\begin{abstract}
This Short Paper intends to present the development of a digital game as part of the extension research: "Architectonic heritage, design and education: development of Playful Interactive Systems (educational games in digital media)" and is part of the work fomented by the Research Group (name withheld for submission). It is intended to emphasize the concept of game as a transmitter of culture and knowledge and to discuss the potentiality of digital game as a tool in assimilation of heritage architecture.
\end{abstract}

Keywords: Digital Game, Digital Drawing, Heritage Education

\section{Introdução}

A crescente abrangência das novas tecnologias permite que os jogos digitais se constituam como uma nova maneira do brincar, principalmente entre as gerações mais novas. Proporcionam novas sensibilidades relativas à interface digital e apresentam-se, cada vez mais, como objeto de debate no meio acadêmico e torna-se possível discutir sua função como elemento cultural e seu potencial como parte do processo cognitivo de assimilação do conhecimento e, mais especificamente, do patrimônio arquitetônico.

O presente resumo apresenta brevemente a elaboração de um "jogo dos sete erros" digital como parte da pesquisa "Patrimônio arquitetônico, design e educação: desenvolvimento de Sistemas Interativos Lúdicos (jogos educativos em meio digital)" e integra os trabalhos fomentados pelo Núcleo de Pesquisa (nome omitido para avaliação). Pretende-se evidenciar a potencialidade do jogo e do desenho digitais como elementos transmissores de cultura arquitetônica e patrimonial e, nesse sentido, ressaltar a contribuição de ferramentas de representação digital e de software de programação no âmbito da arquitetura patrimonial.

Parte-se do princípio de que a arquitetura e a cidade em si são sistemas complexos e de difícil apreensão por parte da população em geral e discute-se a competência do jogo em meio digital como linguagem intermediária na assimilação de valores arquitetônicos e culturais. Através do estudo de
Roger Caillois (1990), afirma-se a importância do jogo e das atividades lúdicas como elementos que se contaminam pela cultura. A "não-seriedade" (HUIZINGA,2000) característica do jogo torna-o atraente para todas as faixas etárias e justificase, dessa forma, a utilização do jogo como assimilador de conhecimento no processo de aprendizagem.

\section{Metodologia}

Assim sendo, apresenta-se o desenvolvimento de um "jogo dos sete erros" digital a ser utilizado como instrumento de suporte na "educação patrimonial" (HORTA, 1999) por professores e alunos da rede de Ensino Público do município de São Carlos. O processo pode, sucintamente, ser dividido em três fases a serem abordadas: preparação do material base, programação do jogo e aplicação teste.

O jogo em meio digital não se dá através de uma materialidade física, retendo-se ao aspecto visual e, nesse sentido, a questão das imagens é considerada de grande importância. Após levantamento fotográfico do conjunto arquitetônico da fazenda Santa Maria do Monjolinho, de interesse patrimonial para o município, foram selecionadas duas fotos para servirem de matriz ao jogo que, a princípio, conta com dois níveis de dificuldade.

No processamento das fotografias, o principio utilizado partiu da busca pela interação de dois recursos gráficos digitais, o desenho e a fotografia, objetivando uma linguagem 
visual que colocasse uma relação mais pessoal do jogador com o conteúdo. $O$ desenho como uma maneira de abstração torna o patrimônio mais apreensível cognitivamente e a fotografia mantém uma conexão com o contexto real e com a questão patrimonial.

Nesse sentido, foi utilizado o software SketchBook Pro da Autodesk por meio de um iPad para a feitura das ilustrações. O programa disponibiliza diversos recursos de desenho e propicia que se trabalhe em cima de imagens através da interação de camadas, fator essencial para o resultado que se desejou atingir. $O$ procedimento é análogo em ambas as imagens: a fotografia base é colocada na camada "mais baixa" e, acima dela, articulam-se três camadas: uma com o traçado das linhas de contorno do desenho, outra abaixo com o colorido das superfícies e, entre estas, uma camada onde se encontram o sombreamento e as texturas.

As colagens originais foram duplicadas para dar origem às imagens com os sete erros. Por meio do Photoshop CS6, foram adicionadas as diferenças: a presença e a sutileza delas em cada par de imagens é o que define a dificuldade do jogo. Devido cuidado foi tomado para evitar que os erros ficassem pequenos demais para a tela do iPad e que ficassem evidentes demais, para permitir a jogabilidade do jogo, mantendo certo desafio que motive o interesse.

Com o material gráfico finalizado, para a programação do jogodosseteerrosbuscou-seum programa dedesenvolvimento de jogos bidimensionais disponível gratuitamente e com interface acessível, que permitisse a feitura de um sistema relativamente simples sem a necessidade de aprofundamentos em linguagem de programação. Outro importante critério de escolha foi a possibilidade de desenvolver jogos para iPad, visando maior acessibilidade e a necessidade de levar os jogos até as escolas.

O software selecionado para tanto foi o GameSalad beta v. 0.10.5, cujo código se dá em analogia à linguagem cênica: o processo de programação de um jogo é colocado como a criação de uma peça de teatro, o que torna o procedimento mais acessível. O funcionamento do GameSalad se dá através de alguns elementos teatrais: a peça (o jogo em si), que se divide em cenas (salas), onde os atores (peças, personagens) agem dentro de regras, executando comportamentos (ações de jogo, interação com comandos do jogador). Pode-se, ainda, conferir atributos a cada um desses elementos: imagens, tamanho, entre outros.

Para o jogo em questão, foi necessária a criação de quatro tipos de cenas: a) uma tela inicial, que apresenta uma introdução onde o jogador pode escolher a dificuldade do jogo, conduzindo a dois "caminhos" análogos de acordo com o nível escolhido. b) duas telas com as instruções do jogo: uma para o nível médio e outra para o difícil; c) duas salas onde ocorrem os jogos propriamente ditos, com os pares de imagens do casarão e da antiga estação como plano de fundo, respectivamente no nível difícil e médio e d) duas telas finais, com textos informativos sobre a fazenda e sobre a edificação em questão e que conduz o jogador novamente à tela inicial; e dois tipos de atores: atores-botões e atores-erros.

A transição entre as cenas se dá por meio de atores-botões, ou seja, atores cujo comportamento principal é conduzir à cena conseguinte. Somente no caso da passagem de (c) para (d), a transição se dá automaticamente, quando todos os atoreserros já executaram seus comportamentos.

Nas cenas onde ocorre o jogo dos sete erros propriamente dito é onde se dá a ação dos atores-erros. Cada um destes representa uma diferença entre as imagens e, materializados no símbolo de $\mathrm{X}$ vermelhos, são posicionados adequadamente sobre a imagem da direita. Cada erro, então, é submetido à seguinte regra: deve permanecer oculto até que o jogador clique sobre determinada região da figura e, só então aparecer. O comportamento definido para cada ator-erro é tornar-se visível quando solicitado, quando se clica na região em que ele está ocultamente posicionado.

Finalizada a programação no GameSalad, o resultado foi publicado online e foi gerado um link para que o jogo pudesse ser acessado em diferentes dispositivos por meio de um navegador, sem a necessidade de instalação de um software adicional. Isto amplia e facilita o acesso ao jogo e, por outro, torna o funcionamento e o desempenho do jogo dependentes da velocidade de conexão à internet disponível.

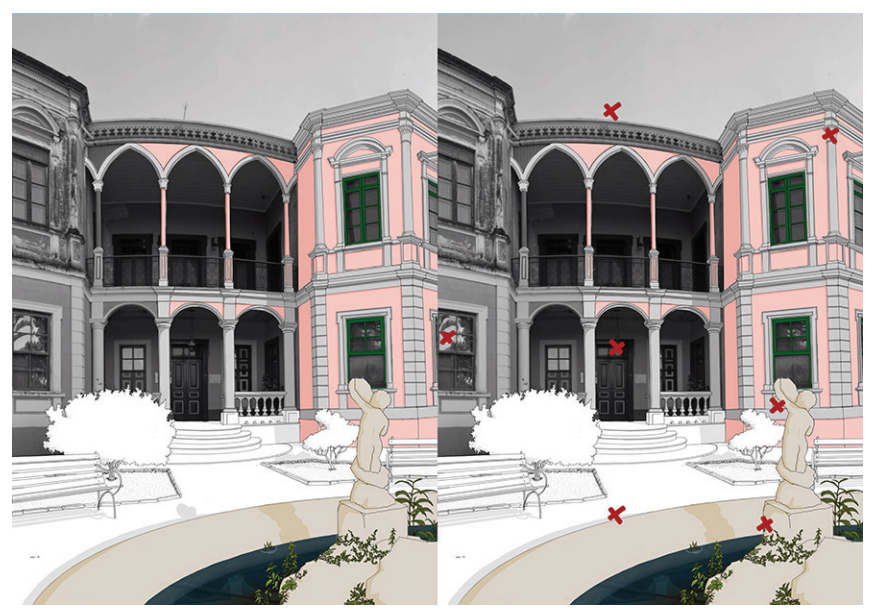

Figura 1: interface do jogo dos sete erros de nível difícil. Próprio autor, 2015.

Com o jogo pronto e publicado, os primeiros testes foram realizados com estudantes do Instituto (omitido para avaliação) por meio de IPads fornecidos pelo núcleo de pesquisa: cerca de $10 \%$ do total de alunos (23 alunos entre 17 e 23 anos) de graduação do instituto se dispuseram a jogá-lo e responder um formulário elaborado previamente com questões referentes à jogabilidade e a outros aspectos do jogo.

Além disso, foi realizada uma segunda aplicação do jogo com alunos do projeto Pequeno Cidadão da USP campus de São Carlos com idades entre 10 e 14 anos por meio dos IPads novamente acompanhada por um questionário. A aplicação contou com um grupo pequeno de crianças porém as respostas aos questionários indicam para resultados interessantes. 


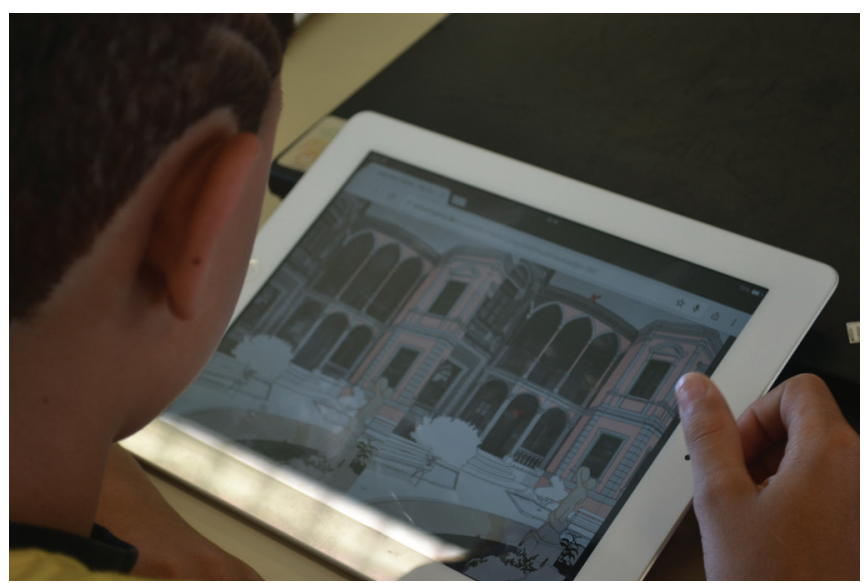

Figura 2: aplicação do jogo junto ao projeto Pequeno Cidadão. Próprio autor, 2015.

\section{Resultados}

Dos 20 jogadores com idades entre 17 e 24 anos,
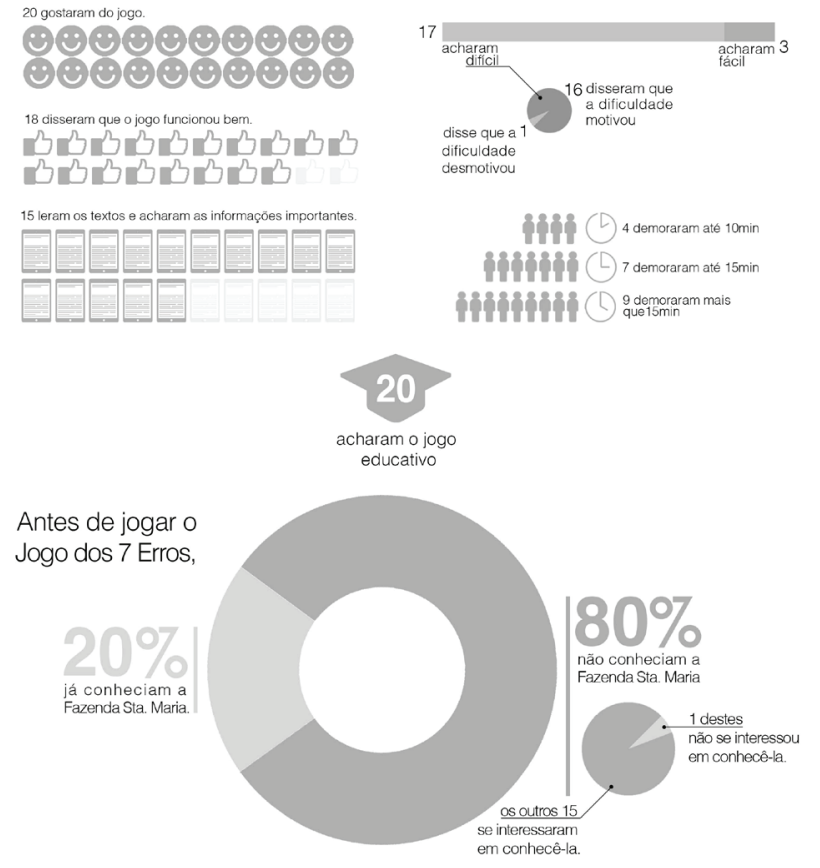

O que as pessoas mais gostaram no jogo:

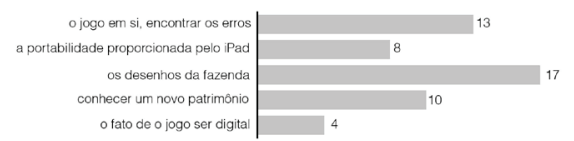

Figura 3: gráfico resultante das respostas ao questionário. Próprio autor, 2015.
A partir da análise das respostas, observou-se uma boa jogabilidade, algumas vezes interferida pela velocidade da internet, mas sem que isto gerasse grandes problemas. Como pode-se observar no gráfico da figura 3 , a maioria absoluta daqueles que participaram do teste acharam o jogo difícil, mas todos que assim o descreveram disseram que a dificuldade foi um fator de motivação. O tempo médio de execução ficou entre 10 minutos para o nível médio e 20 para o nível difícil. Todos os participantes do primeiro teste acharam o jogo educativo.

A maior parte partes daqueles que responderam o questionário não conhecia a Fazenda Santa Maria antes de jogar o jogo e, depois de o jogarem, praticamente todos aqueles que não a conheciam sentiram motivados em visitála. Nota-se, ainda, por meio das respostas ao questionário, que os desenhos da fazenda, bem como o a portabilidade do jogo digital por meio dos iPads chamaram a atenção positivamente dos jogadores.

Na segunda aplicação, é interessante notar que todas as crianças que jogaram o jogo e não conheciam a fazenda se interessaram em conhece-la e todas aquelas que já a conheciam, conseguiram reconhece-la nas imagens do jogo.

\section{Discussão}

Os resultados das aplicações dão indícios da competência do jogo digital como ferramenta de aprendizado na disseminação da arquitetura patrimonial, apesar de se tratar de pequenas amostragens. Constata-se seu potencial como ferramenta de auxílio na educação e justifica-se, dessa maneira, a sua aplicação como meio de divulgação do patrimônio cultural de São Carlos junto a comunidade do município.

Bem como todas as atividades lúdicas, o jogo digital propicia uma forma divertida e descontraída de assimilação do conhecimento que, somada à experiência proporcionada pela interface digital e à acessibilidade proporcionada pelo iPad, estimula a busca pelo aprendizado. Por fim, cabe ressaltar a importância da programação e de desenho através das ferramentas digitais que tornam possível a realização e aplicação do jogo.

\section{Referências}

Caillois, R. Os jogos e os homens. Lisboa: Cotovia, 1990.

Huizinga, J. Homo Ludens: O Jogo como Elemento de Cultura. São Paulo: Perspectiva, 2000, $4^{\circ}$ edição.

Horta, M. L. P., Grumberg, E. \& Monteiro, A. Q. Guia Básico da Educação Patrimonial. Brasília: Instituto do Patrimônio Artístico Nacional, Museu Imperial, 1999. 